\title{
Nutrient-Based Chemical Library as a Source of Energy Metabolism Modulators
}

\section{$\operatorname{AUTHOR}(\mathrm{S})$ :}

Furuta, Tomoyuki; Mizukami, Yuya; Asano, Lisa; Kotake, Kenjiro; Ziegler, Slava; Yoshida, Hiroki; Watanabe, Mizuki; ... Waldmann, Herbert; Nishikawa, Makiya; Uesugi, Motonari

\section{CITATION:}

Furuta, Tomoyuki ...[et al]. Nutrient-Based Chemical Library as a Source of Energy Metabolism Modulators. ACS Chemical Biology 2019, 14(9): 1860-1865

\section{ISSUE DATE:}

\section{9-9-20}

\section{URL:}

http://hdl.handle.net/2433/244838

\section{RIGHT:}

This document is the Accepted Manuscript version of a Published Work that appeared in final form in 'ACS Chemical Biology', copyright (c) American Chemical Society after peer review and technical editing by the publisher. To access the final edited and published work see https://doi.org/10.1021/acschembio.9b00444.; The full-text file will be made open to the public on 22 August 2020 in accordance with publisher's 'Terms and Conditions for Self-Archiving'.; この論文は出 版社版でありません。引用の際には出版社版をご確認ご利用ください。; This is not the published version. Please cite only the published version. 


\title{
Nutrient-Based Chemical Library as a Source of Energy Metabolism Modulators
}

\author{
Tomoyuki Furuta, ${ }^{\dagger}$ Yuya Mizukami, ${ }^{\ddagger}$ Lisa Asano, ${ }^{\dagger}$ Kenjiro Kotake, ${ }^{\dagger}$ Slava Ziegler, ${ }^{\prime}$ Hiroki Yo- \\ shida, ${ }^{\dagger}$ Mizuki Watanabe, ${ }^{\dagger}$ Shin-ichi Sato, ${ }^{\dagger}$ Herbert Waldmann, "Makiya Nishikawa, ${ }^{*,, \S}$ and Mo- \\ tonari Uesugi ${ }^{*, \dagger, \perp, \#}$
}

${ }^{\dagger}$ Institute for Chemical Research and Institute for Integrated Cell-Material Sciences (WPI-iCeMS), Kyoto University, Uji, Kyoto, 611-oo11, Japan

${ }^{\ddagger}$ Department of Biopharmaceutics and Drug Metabolism, Graduate School of Pharmaceutical Sciences, Kyoto University, Sakyo-ku, Kyoto 6o6-8501, Japan

"Max Planck Institute of Molecular Physiology, Otto-Hahn-Strasse 11, 44227 Dortmund, Germany

$\$$ Laboratory of Biopharmaceutics, Faculty of Pharmaceutical Sciences, Tokyo University of Science, 2641 Yamazaki,

Noda, Chiba 278-8510, Japan

${ }^{\perp}$ RIKEN-Max Planck Joint Research Division for Systems Chemical Biology, RIKEN Center for Sustainable Resource Science, 2-1 Hirosawa, Wako, Saitama 351-0198, Japan

\# School of Pharmacy, Fudan University, Shanghai 201203, China

\section{Supporting Information Placeholder}

\section{INTRODUCTION}

Carbohydrates, lipids, amino acids, and vitamins constitute some of the nutrients essential for the life of an organism. On the other hand, there exist a number of pharmaceuticals and functional foods that consist of covalently conjugated multiple nutrients. For example, tocopherol nicotinate, a clinically used lipid antioxidant (Figure $\left.\mathrm{S}_{1} \mathrm{~A}\right),{ }^{1}$ is a synthetic conjugate of vitamins $\mathrm{E}$ and $\mathrm{B}_{3}$. Another example is a conjugate of vitamin $\mathrm{C}$ and glucose, $\mathrm{AA}-2 \mathrm{G}$ (Figure $\mathrm{S} 1 \mathrm{~B}) .^{2}$ This long-acting prodrug, used as a component of cosmetics and

supplements, is enzymatically metabolized to gradually release vitamin $C$ and glucose. The nutrient conjugates exemplified by these two examples tend to show greater potency than a mixture of the individual components and more predictable safety profiles than completely unnatural chemical entities.

A large number of nutrient conjugates are also naturally occurring in organisms. For example, NA-Gly, a conjugate of arachidonic acid and glycine (Figure $\mathrm{S}_{1} \mathrm{C}$ ), plays distinct roles from those of the parental nutrients, including inhibition of T-type calcium channel and fatty acid amide hydrolase. ${ }^{3}$ These considerations led to the hypothesis that combinatorial chemical synthesis of covalent nutrient conjugates produces a focused chemical library that potentially contain unique, relatively safe biologically active molecules.

\section{RESULTS AND DISCUSSION}

To construct a library of nutrient conjugates, we employed Ugi reaction, a four-component reaction involving a ketone or aldehyde, an amine, an isocyanide, and a carboxylic acid to form a bis-amide 4 (Scheme 1). The use of Ugi reaction for chemical library construction is not new: a number of other studies have generated chemical libraries through the multi-component one-pot reaction. ${ }^{5,6}$ Nevertheless, it has never been used for constructing a library of nutrient conjugates. Reaction components were chosen mainly from nutrients or their precursors that are often included in multivitamin supplements: 20 fatty acids and 3 vitamins as carboxylic acid components; glucosamine and a vitamin, two monoamines, 4 amino acids, and two biologically active peptides (VPP7 and carnosine ${ }^{8,9}$ ) as amine components, 3 alde- 
hydes corresponding to glycine, valine, phenylalanine; and ethyl isocyanoacetate to form a glycine ester terminus. Combinatorial parallel Ugi reactions of these components yielded 308 nutrient conjugates. Purities of the desired products were checked by LC-MS, and reaction yields ranged from 2.7$83 \%$ (Table $\mathrm{S}_{1}$ ).

\section{Scheme 1. Construction of Nutrient Oriented Chemi-} cal Library

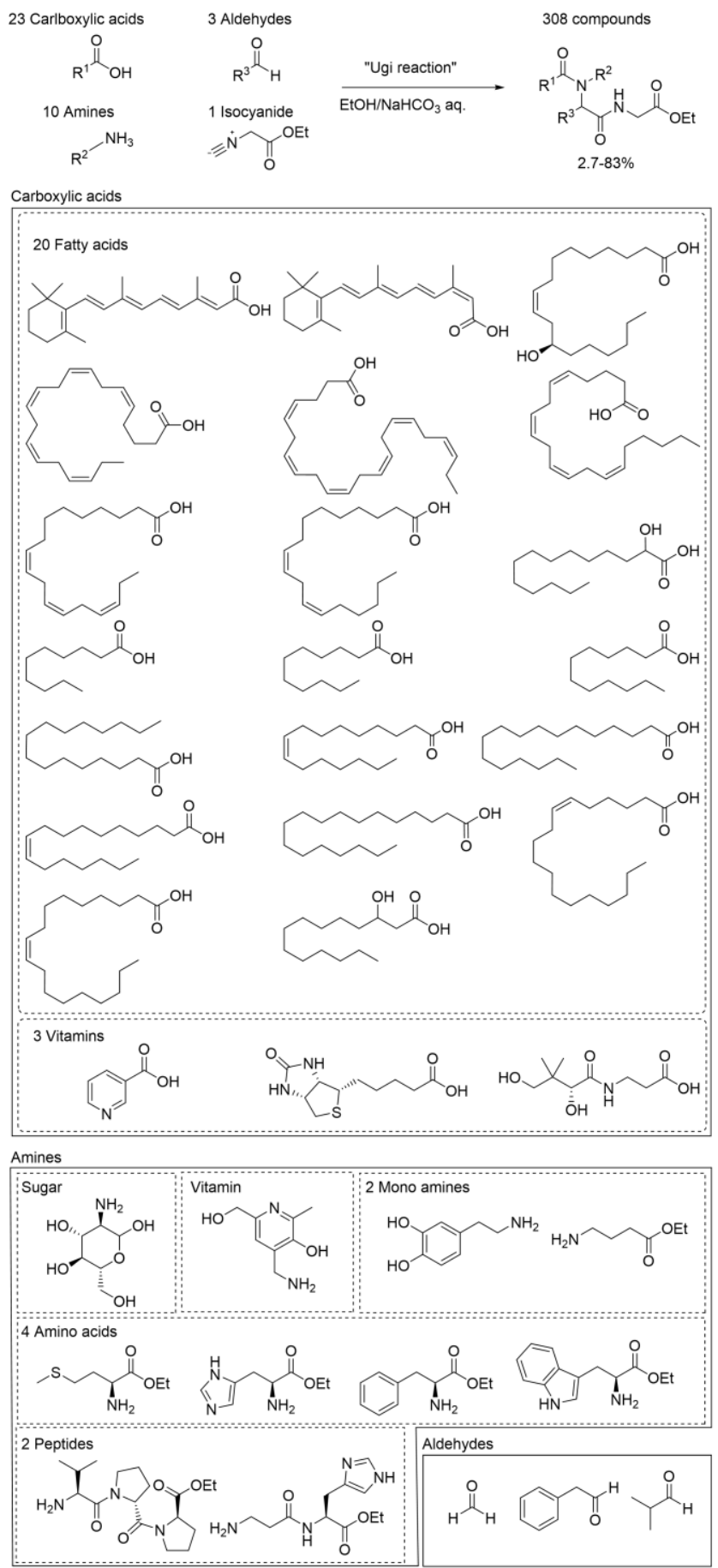

One biological activity expected from these nutrient conjugates was the modulation of energy metabolism in mammalian cells. For proof of concept, we screened the library by using a reporter gene of sterol regulatory element-binding protein (SREBP), a master transcription factor of lipogenesis. ${ }^{10}$ SREBP is positioned in the far downstream of mamma- lian energy metabolism pathways, ${ }^{11}$ so that the SREBP reporter gene activity serves as an indicator for a myriad of cellular metabolic alterations. Chinese hamster ovary ( $\mathrm{CHO})-\mathrm{K}$ i cells were transfected with the SREBP reporter gene in which the expression of firefly luciferase is controlled by three SREBP binding sites. A constitutively active $\beta$-Gal reporter gene was also co-transfected for normalization purposes. ${ }^{12}$ We conducted initial screening at $10 \mu \mathrm{M}$ of the compounds and selected screening hits that exhibited SREBP inhibition higher than that of 25-hydoroxycholesterol (HC), a known endogenous inhibitor of SREBP, after $24^{-h}$ incubation (Table $\mathrm{S} 1$ ). Repeated experiments identified 5 conjugates that showed clear dose-dependence (Figure S2). Of the five conjugates, three molecules were structurally analogous (Figure S2), and the most potent molecule was molecule $\mathbf{1}$, which is composed of DHA, glucosamine, and phenylalanine-glycine dipeptide (Figure $1 \mathrm{~A}$ ). We therefore focused our efforts on molecule $\mathbf{1}$ (also referred to as DHG) for further investigations.

A
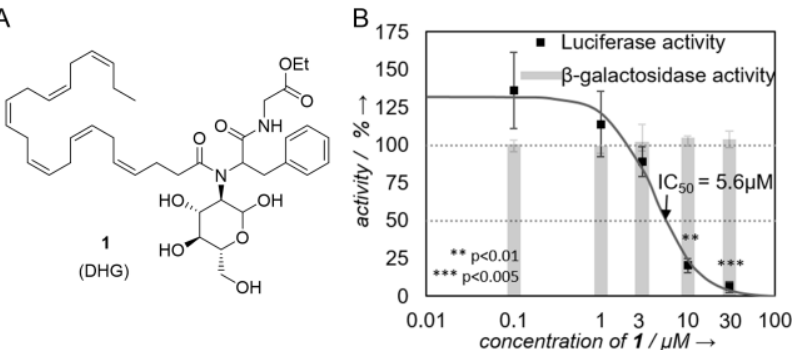

C
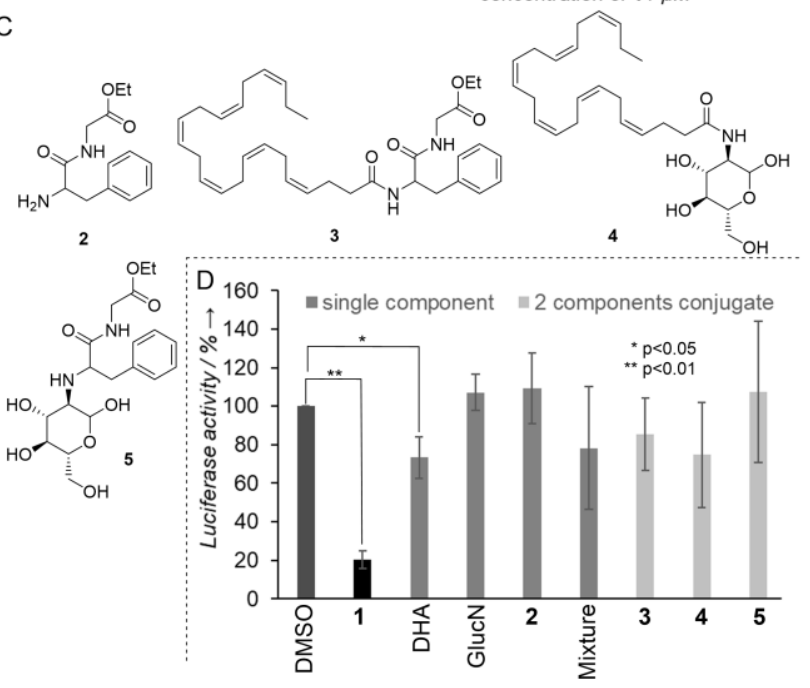

Figure 1. Chemical structure of molecule 1 and its SREBP inhibitory activity. (A) Chemical structure of molecule 1 (DHG). (B) Dose response curve for molecule 1. Molecule 1 suppressed the ability of endogenous SREBPs to activate transcription of a luciferase reporter gene. The $\mathrm{IC}_{50}$ value was estimated to be $5.6 \mu \mathrm{M}$ from a four-parameter logistic model fitting curve (Image J). The $\beta$-galactosidase activity showed no detectable change in the tested concentrations of molecule 1. (C) Chemical structures of dipeptide 2 and twocomponents conjugates (3-5). (D) SREBP inhibitory activities of molecules 1-5. Luciferase activities were measured at a concentration of $10 \mu \mathrm{M}$ after 24 -h incubation. Each single component (DHA, glucosamine [GlucN], and dipeptide 2 ) or their mixture exhibited weaker activity than molecule $\mathbf{1}$. The two-components conjugates (3-5) also displayed weaker activities than molecule $\mathbf{1}$. 
The $\mathrm{IC}_{50}$ value of molecule $\mathbf{1}$ for the SREBP reporter gene was estimated to be $5.6 \mu \mathrm{M}$, while its effects on the $\beta$-Gal reporter gene up to $30 \mu \mathrm{M}$ were undetectable, indicating that 24-hour incubation with molecule 1 has no detectable cytotoxicity up to $30 \mu \mathrm{M}$ (Figure $1 \mathrm{~B}$ ). We examined the ability of each of the components (DHA, glucosamine, and phenylalanine-glycine dipeptide 2) to inhibit SREBP at $10 \mu \mathrm{M}$ (Figure ${ }_{1 D)}$. Although DHA was found to be slightly active, as previously reported, ${ }^{13}$ the other two were essentially inactive. Importantly, the activity of a mixture of the three components was as low as that of DHA. We chemically synthesized three partial structures of molecule $\mathbf{1}$ by combining two of the components (molecules 3-5) (Figure $1 \mathrm{C}$ ). Although molecules 3 and 5, which contain DHA, exhibited activity similar to that of DHA, the partial structures failed to exert clear inhibitory activity at 10 $\mu \mathrm{M}$ (Figure $1 \mathrm{D})$. These results indicate that covalent conjugation of all the three components is required for the potent activity of molecule $\mathbf{1}$.

To gain insights into the mechanism of action, we examined the status of an SREBP protein upon treatment with molecule 1. Newly synthesized SREBPs are localized on the endoplasmic reticulum (ER) membrane, where they bind to SREBP cleavage-activating protein (SCAP), an escort protein of SREBPs. ${ }^{14,15}$ At low levels of cellular sterol, the SREBPSCAP complex is transported from the ER to the Golgi apparatus, where SREBPs are cleaved sequentially by site-1 protease $\left(\mathrm{S}_{1} \mathrm{P}\right)$ and site-2 protease $\left(\mathrm{S}_{2} \mathrm{P}\right)$, liberating the $\mathrm{NH}_{2}$ terminal transcription factor domain of SREBPs. ${ }^{10,16}$ The mature form translocates to the nucleus, where it activates lipogenic genes. ${ }^{10}$ The activation of SREBPs is tightly regulated by a negative feedback loop in which cholesterol and $25^{-}$ hydroxycholesterol (25-HC) bind to SCAP and Insigs (ER anchor proteins), respectively, resulting in retention of the SREBP-SCAP complex in the ER. ${ }^{17,18}$ Western blot analysis of SREBP-2 in CHO-K1 cells indicates that molecule 1 decreases the amounts of the mature form and accumulates the precursor form until $6 \mathrm{~h}$ of incubation, much like 25-HC (Figure $2 \mathrm{~A})$. However, prolonged treatment with molecule 1 decreased the amounts of the precursor, whereas 25 -HC did not (Figure 2A). Since SREBP proteins are unstable once released from SCAP, 19,20,21 molecule $\mathbf{1}$ is likely to inhibit the activation process of SREBP-2 posterior to its release from SCAP unlike 25-HC does.

The relatively large structure of molecule 1 (molecular weight: 722.92) prompted us to estimate its membrane permeability. Parallel artificial membrane permeability assay (PAMPA) showed a limited permeability of molecule $\mathbf{1}$ through a lipid-infused artificial membrane (Mean Papp: 1.19 $\mathrm{x} 10^{-6} \mathrm{~cm} / \mathrm{s}$ ). The low membrane permeability increased the possibility that molecule $\mathbf{1}$ either targets extracellular proteins or is actively transported into cells. A number of studies have shown that covalent conjugations of nutrients and vitamins increases active transport of pharmaceuticals. ${ }^{22,23}$

The presence of a glucose unit in molecule $\mathbf{1}$ encouraged us to examine the effects of glucose transporter inhibitors on the activity of molecule $\mathbf{1}$. Glucose is known to be transported by two classes of transporters: glucose transporters (GLUTs) or sodium-glucose transport proteins (SGLTs). To our surprise, western blot analyses of SREBP-2 in CHO-K1 cells revealed that co-incubation with phloretin, a representative GLUT inhibitor, enhanced the ability of molecule $\mathbf{1}$ to decrease the protein levels of SREBP-2, while that with phlorizin, a representative SGLT inhibitor, failed to do so (Figure $2 \mathrm{~B}$ ). Importantly, phloretin alone, but not phlorizin, decreased the amounts of both the mature and precursor forms of SREBP-2 in CHO-K1 cells, although not as potently as molecule $\mathbf{1}$ did (Figure $2 \mathrm{~B}$ ). These results imply that molecule 1 impairs SREBP-2 activation by inhibiting GLUTs rather than by being transported through GLUTs.

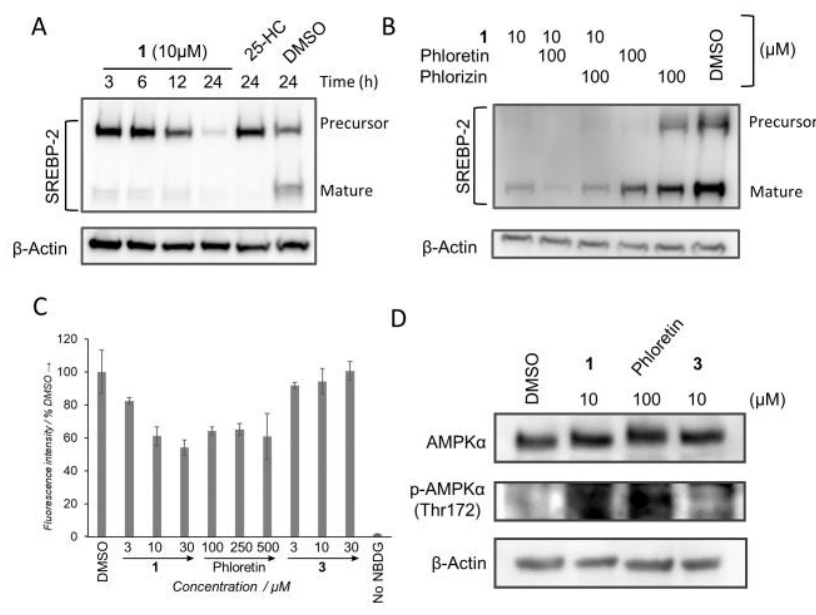

Figure 2. Mechanistic analysis of molecule 1 (A) Effects of molecule 1 on the SREBP-2 maturation. CHO-K1 cells were treated with molecule $\mathbf{1}(10 \mu \mathrm{M})$ or 25 -hydroxycholesterol (5 $\mu \mathrm{M}$ ) for varied lengths of time, and the cell lysates were analyzed by western blots with an SREBP-2 antibody. Positions of precursor and mature forms of SREBP-2 are indicated on the right. (B) Effects of transporter inhibitors on the SREBP-2 maturation. Glucose transporter (GLUT) inhibitor phloretin $(100 \mu \mathrm{M})$ or sodium-glucose transport protein (SGLT) inhibitor phlorizin $(100 \mu \mathrm{M})$ were added to the culture medium of $\mathrm{CHO}-\mathrm{K}_{1}$ cells in the presence or absence of molecule 1 (10 $\mu \mathrm{M}$ ). After 24-hour incubation, the cell lysates were analyzed by western blots with an SREBP-2 antibody. Positions of precursor and mature forms of SREBP-2 are indicated on the right. (C) Inhibition of cellular glucose uptake by molecule 1 . Uptake of fluorescently-labeled glucose analog 2-NBDG was measured with human Caco-2 cells. The cells were treated simultaneously with NBDG $(200 \mu \mathrm{M})$ and varied concentrations of molecule $1(3-30 \mu \mathrm{M})$, molecule $3(3-30 \mu \mathrm{M})$, or positive control phloretin $(100-500 \mu \mathrm{M})$. After extensive wash, fluorescence of the cells was measured with a fluorescence plate reader (excitation: $490 \mathrm{~nm}$; emission: $530 \mathrm{~nm}$ ). (D) AMPK activation by molecule 1. Hepa 1- 6 cells were treated with molecule $1(10 \mu \mathrm{M})$, phloretin $(100 \mu \mathrm{M})$, or molecule 3 (10 $\mu \mathrm{M})$, and the cell lysates were analyzed by western blots with an antibody specific for phosphor-Thriz2 AMPK. It is evident that molecule $\mathbf{1}$ activates AMPK phosphorylation just like phloretin.

To support the hypothesis, we next examined the ability of molecule $\mathbf{1}$ to block glucose uptake of differentiated Caco2 cells, a human intestinal cell line that expresses GLUTs, especially GLUT2 ${ }^{24}$ Molecule 1 blocked cellular uptake of the fluorescently-labeled glucose analog 2-NBDG (2-(N-(7nitrobenz-2-oxa-1,3-diazol-4-yl)amino)-2-deoxyglucose $)^{25,26}$ in a dose-dependent manner, whereas a control molecule that lacks the sugar moiety of molecule 1 (molecule 3 ) had little effects. No apparent cell death was observed during the course of the 3-hour study. The inhibitory activity of mole- 
cule 1 at $10 \mu \mathrm{M}$ was comparable to that of high concentrations of phloretin (Figure $2 \mathrm{C}$ ).

There are four major glucose transporters in human cells: GLUT1-4 (SLC2A1-4). Overexpression of each glucose transporter increased glucose uptake in HEK293 cells, and the ability of molecule $\mathbf{1}$ to cancel the increase was examined. The results (Figure $\mathrm{S}_{3}$ ) suggest that molecule 1 exhibits broad selectivity to glucose transporters. Stronger inhibition was observed for GLUT2-4 than for GLUT1, which is consistent with the results of Caco-2 cells whose major glucose transporter is GLUT2. ${ }^{24,27}$

Inhibition of cellular glucose uptake usually results in a shortage of intracellular energy, leading to the activation of AMP-activated protein kinase (AMPK), a sensor of cellular energy and nutrient status. ${ }^{28,29}$ It has also been demonstrated that the activation of AMPK induces phosphorylation of SREBPs to block the nuclear translocation of SREBPs, so that the cells terminate lipogenesis upon limited availability of cellular energy..$^{\circ}$ Western blot analyses with an antibody against phospho-AMPK indicate that 3 -hour treatment of Hepar- 6 cells with molecule $1(10 \mu \mathrm{M})$ induced the Thri72 phosphorylation of AMPK as much as that with phloretin $(100 \mu \mathrm{M})$ did, whereas three partial structures of molecule $\mathbf{1}$ (molecules 3-5) failed to induce the phosphorylation of AMPK (Figure 2D and Figure $\mathrm{S}_{4}$ ). At this moment, we cannot rule out the possibility that molecule $\mathbf{1}$ has SREBP-inhibition mechanisms other than the energy depleting activity. Nonetheless, the inhibition of glucose transporters and the subsequent activation of AMPK provides one possible explanation for the observed SREBP inhibition in the cultured cells.

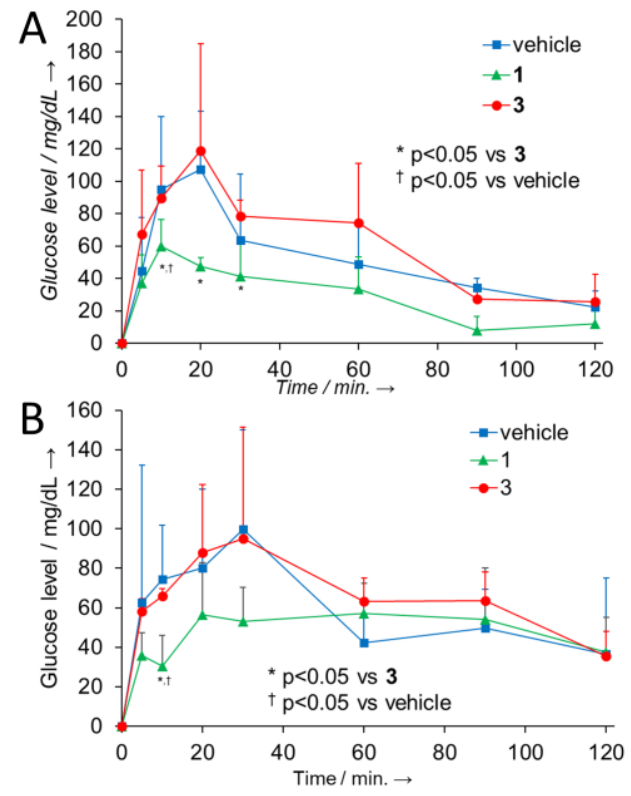

Figure 3. Glucose uptake in fasted mice. (A) Oral coadministration of molecule $\mathbf{1}$ and glucose. Molecule $\mathbf{1}(6.25$ $\mu \mathrm{mol})$ or molecule $3(6.25 \mu \mathrm{mol})$ was orally co-administrated into fasted mice $(n=3)$ with glucose $(12.5 \mathrm{mg})$ in water $(250$ $\mu \mathrm{L})$. (B) Pretreatment with molecule 1 prior to glucose oral administration. Molecule $\mathbf{1}(6.25 \mu \mathrm{mol})$ or molecule 3 (6.25 $\mu \mathrm{mol})$ was orally administrated into fasted mice $(\mathrm{n}=3) 10-\mathrm{min}$ before oral administration of glucose $(12.5 \mathrm{mg})$ in water $(250$ $\mu \mathrm{L})$. Blood samples were collected at indicated time points and analyzed by a blood glucose self-monitoring kit.
The glucose uptake inhibitory activity in Caco-2 cells and the limited cell permeability of molecule $\mathbf{1}$ encouraged us to examine the effects of orally administered molecule 1 on intestinal absorption of glucose in mice. Mice were fasted for 24-hours prior to oral administration of a glucose solution comparable to typical sweetened beverage products. Oral coadministration of molecule 1 (Figure $3 \mathrm{~A}$ ) or its administration 10 min prior to the glucose administration (Figure ${ }_{3} \mathrm{~B}$ ) significantly suppressed the increase of blood glucose levels. In contrast, molecule 3, which is devoid of the glucose segment, exhibited no detectable effects. We found no apparent toxicity of molecule $\mathbf{1}$ in mice such as diarrhea during the course of the experiments. Although the suppression of blood glucose levels may not necessarily due to the inhibition of glucose transporters, these animal effects were consistent with the glucose uptake inhibition observed in the cultured cells.

In the present study, a chemical library of 308 covalent conjugates of multiple nutrients and vitamins led to the discovery of molecule $\mathbf{1}$ as a new inhibitor of glucose uptake in vitro and in vivo. It remains unclear how this particular nutrient conjugate blocks glucose uptake. Perhaps the glucose moiety of molecule 1 may be recognized by glucose transporters, but the hydrophobic DHA tail and bulky dipeptide segment could prevent the transport of the entire molecule.

Close inspection of the screening results indicates the two major structural requirements for the activity. First, the molecule 1 analogs with unsaturated fatty acids tend to be more potent than those with saturated fatty acids (Figure $\mathrm{S}_{5}$ ). Covalent conjugates of unsaturated fatty acids and glycine have been reported to block glycine transporters. ${ }^{31}$ Although it remains unknown why unsaturated fatty acids work better than saturated fatty acids, covalent conjugation of unsaturated fatty acids with nutrients might provide a general strategy to designing nutrient transporter inhibitors.

Second, replacement of the phenylalanine segment with glycine or valine impairs the activity (Figure S6). A number of glucose transporter inhibitors have been documented in the literature..$^{2}$ One recently reported GLUT1 inhibitor has a peptidic structure containing a fluorinated phenylalanine component and two other phenyl groups, all of which interact extensively with the transporter near the glucose-binding poket. 33 The phenylalanine segment of molecule 1 might similarly assist the interaction of molecule $\mathbf{1}$ in the glucosebinding pocket.

In conclusion, we report the construction of a focused chemical library of 308 covalent conjugates of a variety of small-molecule nutrients. The utility of the library was demonstrated by isolation of new SREBP inhibitors that target glucose transporters. The nutrient conjugates are expected to exert a myriad of biological activities due to the fact that each nutrient component per se plays certain physiological roles. On the other hand, it also means that such a conjugate might display multiple distinct activities. We checked whether molecule $\mathbf{1}$ modulates the activity of LXR, a nuclear receptor that controls the expression of SREBP in response to a number of nutrients including 25 - $\mathrm{HC}$ and glucose.34,35 Reporter gene assays indicate that molecule 1 exhibited no significant effects on LXR (Figure $\mathrm{S}_{7}$ ). Effects of molecule $\mathbf{1}$ on the enzymatic activity of hexokinase, another glucose-binding protein, were also examined in vitro and found to be negligible (Figure S8). Although we cannot conclude 
that molecule $\mathbf{1}$ is truly specific to glucose transporters, such covalent conjugations modulate the selectivity of the nutrients to their original targets. Expansion of nutrient-based chemical libraries would provide invaluable source of novel chemical tools and pharmaceutical seeds that modulate energy metabolism.

\section{ASSOCIATED CONTENT}

\section{Supporting Information}

The Supporting Information is available free of charge on the ACS Publications website at DOI: @@@. The PDF file includes details of experimental methods and supporting figures (PDF).

\section{AUTHOR INFORMATION}

\section{Corresponding Author}

*E-mail uesugi@scl.kyoto-u.ac.jp (M.U.). makiya@rs.tus.ac.jp (M.N.)

\section{Notes}

The authors declare no competing financial interests.

\section{ACKNOWLEDGMENT}

This work was supported by JSPS (17Ho6408 and 26220206 to M.U.). The authors thank F. Quiocho for comments for the manuscript. This work was inspired by the international and interdisciplinary environments of WPI-iCeMS, JSPS A3 Foresight Program "Asian Chemical Probe Research Hub," and JSPS CORE-to-CORE Program "Asian Chemical Biology Initiative." This study used $600-\mathrm{MHz}$ and $800-\mathrm{MHz}$ NMR spectrometers in the Joint Usage/Research Center (JURC) at the Institute for Chemical Research, Kyoto University.

\section{REFERENCES}

(1) Duncan, K. R.; Suzuki, Y. J. Vitamin E Nicotinate. Antioxidants $2017,6,20$.

(2) Yamamoto, I.; Muto, N.; Nagata, E.; Nakamura, T.; Suzuki, Y. Formation of a stable L-ascorbic acid $\alpha$-glucoside by mammalian $\alpha$ glucosidase-catalyzed transglucosylation. Biochim. Biophys. Acta. 1990, 1035, 44.

(3) Connor, M.; Vaughan, C. W.; Vandenberg, J. R. N - Acyl amino acids and $N$ - acyl neurotransmitter conjugates: neuromodulators and probes for new drug targets. Br. J. Pharmacol. 2010, $160,1857$.

(4) Ugi, I. The $\alpha$-Addition of Immonium Ions and Anions to Isonitriles Accompanied by Secondary Reactions. Angew. Chem., Int. Ed. Engl. 1962, 1, 8.

(5) Ugi, I.; Gobel, M.; Gruber, B.; Heilingbrunner, M.; Heiß, C; Hörl, W.; Kern, O.; Starnecker, M.; Dömling, A. Molecular libraries in liquid phase via UGI-MCR. Res. Chem. Intermed. 1996, 22, 625.

(6) Dömling, A. Recent Developments in Isocyanide Based Multicomponent Reactions in Applied Chemistry. Chem. Rev. 2006, 106, 17.

(7) Nakamura, Y.; Yamamoto, N.; Sakai, K.; Okubo, A.; Yamazaki, S.; Takano, T. Purification and Characterization of Angiotensin IConverting Enzyme Inhibitors from Sour Milk. J. Dairy Sci. 1995, 78, 777 .

(8) Kohen, R.; Yamamoto, Y.; Cundy, K. C.; Ames, B. N. Antioxidant activity of carnosine, homocarnosine, and anserine present in muscle and brain. Proc. Natl. Acad .Sci. U.S.A. 1988, 85, 3175.

(9) Nagai, K.; Niijima, A.; Yamano, T.; Otani, H.; Okumura, N.; Tsuruoka, N.; Nakai, M.; Kiso, Y. Possible Role of L-Carnosine in the Regulation of Blood Glucose through Controlling Autonomic Nerves. Exp. Biol. Med. 2003, 228, 1138.
(10) Brown, M. S.; Goldstein, J. L. The SREBP Pathway: Regulation of Cholesterol Metabolism by Proteolysis of a Membrane-Bound Transcription Factor. Cell 1997, 89, 331

(11) Watanabe, M.; Uesugi, M. Small-molecule inhibitors of SREBP activation - potential for new treatment of metabolic disorders. Med. Chem. Commun. 2013, 4, 1422.

(12) Kamisuki, S.; Mao, Q.; Abu-Elheiga, L.; Gu, Z.; Kugimiya, A.; Kwon, Y.; Shinohara, T.; Kawazoe, Y.; Sato, S.; Asakura, K.; Choo, H. -Y. P.; Sakai, J.; Wakil, S. J.; Uesugi, M. A Small Molecule That Blocks Fat Synthesis By Inhibiting the Activation of SREBP. Chem. Biol. 2009, 16, 882.

(13) Le Jossic-Corcos, C.; Gonthier, C.; Zaghini, I.; Logette, E.; Shechter, I.; Bournot, P. Hepatic farnesyl diphosphate synthase expression is suppressed by polyunsaturated fatty acids. Biochem. J. 2005, 385, 787 .

(14) Hua, X.; Nohturfft, A.; Goldstein, J. L.; Brown, M. S. Sterol Resistance in CHO Cells Traced to Point Mutation in SREBP CleavageActivating Protein. Cell 1996, 87, 415.

(15) Goldstein, J. L.; DeBose-Boyd, R. A.; Brown, M. S. Protein Sensors for Membrane Sterols. Cell 20o6, 124, 35.

(16) Sakai, J.; Duncan, E. A.; Rawson, R. B.; Hua, X.; Brown, M. S.; Goldstein, J. L. Sterol-Regulated Release of SREBP-2 from Cell Membranes Requires Two Sequential Cleavages, One Within a Transmembrane Segment. Cell 1996, 85, 1037.

(17) Radhakrishnan, A.; Sun, L. P.; Kwon, H. J.; Brown, M. S.; Goldstein, J. L. Direct Binding of Cholesterol to the Purified Membrane Region of SCAP: Mechanism for a Sterol-Sensing Domain. Mol. Cell 2004, 15, 259

(18) Yang, T.; Espenshade, P. J.; Wright, M. E.; Yabe, D.; Gong, Y.;Aebersold, R.; Goldstein, J. L.; Brown, M. S. Crucial Step in Cholesterol Homeostasis: Sterols Promote Binding of SCAP to INSIG-1, a Membrane Protein that Facilitates Retention of SREBPs in ER. Cell 2002, 110, 489 .

(19) Rawson, R. B.; DeBose-Boyd, R.; Goldstein, J. L.; Brown, M. S. Failure to cleave sterol regulatory element-binding proteins (SREBPs) causes cholesterol auxotrophy in Chinese hamster ovary cells with genetic absence of SREBP cleavage-activating protein. $J$. Biol. Chem. 1999, 274, 28549.

(20) Moon, Y. A.; Liang, G.; Xie, X.; Frank-Kamenetsky, M.; Fitzgerald, K.; Koteliansky, V.; Brown, M. S.; Goldstein, J. L.; Horton, J. D. The Scap/SREBP pathway is essential for developing diabetic fatty liver and carbohydrate-induced hypertriglyceridemia in animals. Cell Metab. 2012, 15, 240.

(21) Asano, L.; Watanabe, M.; Ryoden, Y.; Usuda, K.; Yamaguchi, T.; Khambu, B.; Takashima, M.; Sato, S. I.; Sakai, J.; Nagasawa, K.; Uesugi, M. Vitamin D Metabolite, 25-Hydroxyvitamin D, Regulates Lipid Metabolism by Inducing Degradation of SREBP/SCAP. Cell Chem. Biol. 2017, 24, 207.

(22) Jaracz, S.; Chen, J.; Kuznetsova, L. V.; Ojima, I. Recent advances in tumor-targeting anticancer drug conjugates. Bioorg. Med. Chem. 2005, 13, 5043 .

(23) Vale, N.; Ferreira, A.; Matos, J.; Fresco, P.; Gouveia, M. J. Amino Acids in the Development of Prodrugs. Molecules 2018, 23, 2318.

(24) Mahraoui, L.; Rodolosse, A.; Barbat, A.; Dussaulx, E.; Zweibaum, A.; Rousset, M.; Brot-Laroche, E. Presence and differential expression of SGLT1, GLUT1, GLUT2, GLUT3 and GLUT 5 hexosetransporter mRNAs in Caco-2 cell clones in relation to cell growth and glucose consumption. Biochem. J. 1994, 298, 629.

(25) Yoshioka, K.; Takahashi, H.; Homma, T.; Saito, M.; Oh, K. -B,; Nemoto, Y.; Matsuoka, H. A novel fluorescent derivative of glucose applicable to the assessment of glucose uptake activity of Escherichia coli. Biochim. Biophys. Acta. 1996, 1289, 5.

(26) Lieder, B.; Hoi, J. K.; Holik, A. -K.; Geissler, K.; Hans, J.; Friedl.; B.; Liszt, K.; Krammer, G. E.; Ley, J. P.; Somoza, V. The flavanone homoeriodictyol increases SGLT-1-mediated glucose uptake but decreases serotonin release in differentiated Caco-2 cells. PLOS ONE 2017, 12, eo171580.

(27) Zheng, Y.; Scow, J. S.; Duenes, J. A.; Sarr, M. G. Mechanisms of glucose uptake in intestinal cell lines: Role of GLUT2. Surgery 2012, 151,13 . 
(28) Salt, I. P.; Johnson, G.; Ashcroft, S. J. H; Hardie, D. G. AMPactivated protein kinase is activated by low glucose in cell lines derived from pancreatic $\beta$ cells, and may regulate insulin release. Biochem. J. 1998, 335, 533.

(29) Cho, S. J.; Moon, J. -S.; Lee, C. -M.; Choi, A. M. K.; StoutDelgado, H. W. Glucose Transporter 1-Dependent Glycolysis Is Increased during Aging-Related Lung Fibrosis, and Phloretin Inhibits Lung Fibrosis. Am. J. Respir. Cell. Mol. Biol. 2017, 56, 521.

(30) Li, Y.; Xu, S.; Mihaylova, M.; Zheng, B.; Hou, X.; Jiang, B.; Park, O.; Luo, Z.; Lefai, E.; Shyy, J. Y-J.; Gao, B.; Wierzbicki, M.; Verbeuren, T. J.; Shaw R. J.; Cohen R. A.; Zang, M. AMPK Phosphorylates and Inhibits SREBP Activity to Attenuate Hepatic Steatosis and Atherosclerosis in Diet-Induced Insulin-Resistant Mice. Cell Metab. 2011, 13, 376.

(31) Wiles, A. L.; Pearlman, R. J.; Rosvall, M.; Aubrey, K. R.; Vandenberg, R. J. N-Arachidonyl-glycine inhibits the glycine transporter, GLYT2a. J. Neurochem. 2006, 99, 781.

(32) Qian, Y.; Wang, X,; Chen, X. Inhibitors of glucose transport and glycolysis as novel anticancer therapeutics. World J. Transl. Med. 2014, 3, 37.

(33) Kapoor, K.; Finer-Moore, J. S.; Pedersen, B. P.; Caboni, L.; Waight, A.; Hillig, R. C.; Bringmann, P.; Heisler, I.; Müller, T.; Siebeneicher, H.; Stroud, R. M. Mechanism of inhibition of human glucose transporter GLUT1 is conserved between cytochalasin B and phenylalanine amides. Proc. Natl. Acad. Sci. U.S.A. 2016, 113, 4711.

(34) Ou, J.; Tu, H.; Shan, B.; Luk, A.; DeBose-Boyd, RA.; Bashmakov, Y.; Goldstein, J. L.; Brown, M. S. Unsaturated fatty acids inhibit transcription of the sterol regulatory element-binding protein-1c (SREBP-1c) gene by antagonizing ligand-dependent activation of the LXR. Proc. Natl. Acad. Sci. U. S. A. 2001, 98, 6027.

(35) Mitro, N.; Mak, P. A.; Vargas, L.; Godio, C.; Hampton, E.; Molteni, V.; Kreusch, A.; Saez, E. The nuclear receptor LXR is a glucose sensor. Nature 2007, 445, 219. 